\title{
The Diagnosis and Treatment of Systemic Lupus Erythematosus
}

\author{
Annegret Kuhn, Gisela Bonsmann, Hans-Joachim Anders, Peter Herzer, \\ Klaus Tenbrock, Matthias Schneider
}

\section{SUMMARY}

Background: Systemic lupus erythematosus (SLE) is an autoimmune disease with a prevalence of $36.7 / 100000$ in Germany and a female/male ratio of 4:1. The clinical course is variable, with a broad spectrum of organ manifestations; lupus nephritis develops in about half of all patients.

Methods: This review is based on a selective search of PubMed and the Cochrane Library, including current guidelines and expert recommendations.

Results: Assessment of clinical symptoms, laboratory findings, and optional biopsy results are the basis for early diagnosis of SLE. All patients should be treated with antimalarials as soon as the diagnosis is confirmed. In particular, hydroxychloroquine is associated with a higher rate of remission, fewer relapses, and reduced damage in the course of the disease, even in lupus nephritis. High-dose glucocorticoids should be given only when acutely indicated; immunosuppressives such as azathioprine, methotrexate, or mycophenolate mofetil may be administered to reduce glucocorticoids, according to the EULAR recommendations. Belimumab was recently approved as add-on therapy in autoantibody-positive SLE patients with high disease activity unresponsive to standard treatment. Short-term induction pulse therapy with low-dose intravenous cyclophosphamide, as well as continued mycophenolate mofetil treatment are advances in lupus nephritis.

Conclusion: The long-term prognosis for SLE has improved markedly in recent decades because of earlier diagnosis and optimized treatment. Further research and randomized controlled trials are needed for the development of specifically targeted therapies.

\section{- Cite this as:}

Kuhn A, Bonsmann G, Anders HJ, Herzer P, Tenbrock K, Schneider M: The diagnosis and treatment of systemic lupus erythematosus. Dtsch Arztebl Int 2015; 112: 423-32. DOI: 10.3238/arztebl.2015.0423

\footnotetext{
Interdisciplinary Center for Clinical Studies (IZKS), University Medical Center, Mainz: Prof. Kuhn, MBA Department of Dermatology, University Hospital of Münster: Dr. Bonsmann Nephrological Center, Department of Medicine IV, University Hospital, LMU München: Prof. Anders

Private practice in internal medicine and rheumatology, München: Prof. Herzer

Department of Pediatric and Adolescent Medicine, University Hospital, RWTH Aachen: PD Dr. Tenbrock

Department of Rheumatology, Düsseldorf University Hospital, Düsseldorf: Prof. Schneider
}

ystemic lupus erythematosus (SLE) is a hetero- geneous autoimmune disease that may involve many different organs and display a variable clinical course. The diagnosis of SLE is based on characteristic clinical findings of the skin, joints, kidneys, and the central nervous system, as well as on serological parameters such as antinuclear antibodies (AI A), in particular antibodies to dsDI A (e1). The various clinical symptoms do not always occur simultaneously and may develop at any stage of the disease. In the early stages, physicians from various disciplines often propose several differential diagnoses, or identify only one aspect of the disease without recognizing the symptoms as part of $\operatorname{SLE}(1, \mathrm{e} 2)$. Fever, fatigue, and arthralgia are the most frequently occurring nonspecific symptoms at disease onset; additional joint swelling or a "butterfly rash"—particularly in women of childbearing age - should prompt consideration of SLE (2). The aim of this article is to provide an updated review on the diagnosis and treatment of SLE, based on a selective survey of the literature in PubMed and the Cochrane Library, including current guidelines and the recommendations of experts with extensive experience in the management of this disease.

\section{Epidemiology and Prognosis}

The prevalence of SLE in Germany in the year 2002 was $36.7 / 100000$, with a $4: 1$ ratio of women to men (3). The prevalence of pediatric-onset SLE is probably lower by a factor of ten (e3). The disease often begins in puberty; if SLE is diagnosed in patients under the age of 5 years, a rare monogenic form may be present. The survival rate has risen significantly in recent decades (1955 vs. 2003: 5-year survival rate 5\% vs. $95 \%$; 10 -year survival rate $0 \%$ vs. $92 \%$ ), mainly due to earlier diagnosis and improved management $(4,5, \mathrm{e} 4)$. During the first years after the onset of SLE, mortality is increased mainly due to disease activity and bacterial infection as a result of high glucocorticoid dosage (e5, e6), while cardiovascular complications predominate in the period beginning 5 years after initial diagnosis (e7, e8).

\section{Classification criteria}

The criteria of the American College of Rheumatology (ACR), first published in 1982 and revised in 1997, can be applied for the classification of $\operatorname{SLE}(6,7$, e9). Four 
BOX 1

\section{Classification of SLE: the Systemic Lupus International Collaborating Clinics (SLICC) Classification Criteria*}

- Clinical criteria

- Acute cutaneous lupus erythematosus (including "butterfly rash")

- Chronic cutaneous lupus erythematosus (e.g., localized or generalized discoid lupus erythematosus)

- Oral ulcers (on palate and/or nose)

- Non-scarring alopecia

- Synovitis ( $\geq 2$ joints) or tenderness on palpation ( $\geq 2$ joints) and morning stiffness ( $\geq 30 \mathrm{~min}$ )

- Serositis (pleurisy or pericardial pain for more than 1 day)

- Renal involvement (single urine: protein/creatinine ratio or 24-hour urine protein, $>0.5 \mathrm{~g}$ )

- Neurological involvement (e.g., seizures, psychosis, myelitis)

- Hemolytic anemia

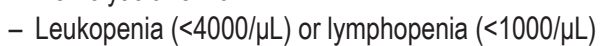

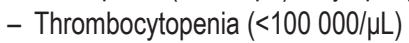

\section{- Immunological criteria}

- ANA level above laboratory reference range

- Anti-dsDNA antibodies

- Anti-Sm antibodies

- Antiphospholipid antibodies (anticardiolipin and anti-ß2-glycoprotein I [lgA-, IgG- or lgM-] antibodies; false-positive VDRL [Venereal Disease Research Laboratory] test)

- Low complement (C3, $\mathrm{C} 4$, or $\mathrm{CH} 50)$

- Direct Coombs test (in the absence of hemolytic anemia)

${ }^{*}$ Modified (short form) after (9).

For classification as SLE, four criteria (at least one of them clinical and at least one immunological) have to be fulfilled or lupus nephritis has to be diagnosed histologically in the presence of ANA or anti-dsDNA antibodies. The SLICC criteria are not diagnostic criteria. SLE, systemic lupus erythematosus of the 11 criteria have to be fulfilled for a diagnosis of SLE. As 4 of the criteria include mucocutaneous lesions, the application of the ACR criteria without analysis of autoantibodies may result in an overestimation of SLE (8, e2). Therefore, the Systemic Lupus International Collaborating Clinics (SLICC) group developed a new set of classification criteria in 2012 (Box 1) (9). Currently both sets of criteria (ACR and SLICC) are often applied simultaneously.

\section{Diagnosis}

\section{Clinical manifestations}

Cutaneous manifestations occur in about $75 \%$ of patients with SLE in the course of the disease, and are the first sign in a quarter of cases (e10). Based on clinical and histological criteria, the skin lesions are divided into lupus erythematosus (LE)-specific (eTable) and LE-non-specific manifestations (e11, e12). The most frequent LE-specific manifestation is the acute cutaneous lupus erythematosus (ACLE), which may occur as a butterfly rash or in the form of a generalized maculopapular exanthema. Discoid lupus erythematosus (DLE) displays a chronic course, typically characterized by inflammatory erythematous plaques with follicular hyperkeratosis and scarring (Figure 1a), leading to irreversible alopecia in hairy areas (Figure 1b). Approximately 5\% of patients with DLE who initially show no systemic organ involvement will develop SLE. Subacute cutaneous lupus erythematosus (SCLE) is characterized by symmetric, annular, polycyclic, and/or papulosquamous/psoriasiform skin lesions without scarring on sun-exposed areas of the back, chest, and extensor surfaces of the arms (Figure 1c). The LE-non-specific manifestations include, among others, vascular skin lesions (e.g., periungual teleangiectasia, livedo racemosa, Raynaud syndrome).

The musculoskeletal system is involved in around $90 \%$ of patients with SLE. In addition to myalgia and arthralgia, arthritis of small and large joints may occur (2). Tendovaginitis and synovitis can be detected by sonography and/or magnetic resonance imaging. Chronic recurring arthritis-particularly of the finger joints-may lead to joint deformation without radiological signs of erosions. This deforming but nondestructive joint disease is termed Jaccoud arthropathy (Figure 1d). About $50 \%$ of patients with SLE develop renal involvement (10). Lupus nephritis is a glomerular nephritis, typically with proteinuria and erythrocyturia (particularly dysmorphic erythrocytes) as well as erythrocyte cylinders in the urinary sediment (Figure 2a). Proteinuria should be quantified in a 24-hour urine sample; a finding of $>0.5 \mathrm{~g} /$ day is usually an indication for renal biopsy. The 2003 revision of the histological classification of lupus nephritis distinguishes six forms (class I to VI), which require a differentiated treatment strategy $(7,11)$. The most commonly occurring cardiovascular manifestations of SLE include Libman-Sacks endocarditis, as well as pericarditis or myocarditis and coronary arteritis. Early occurrence of arteriosclerosis and the associated complications are 

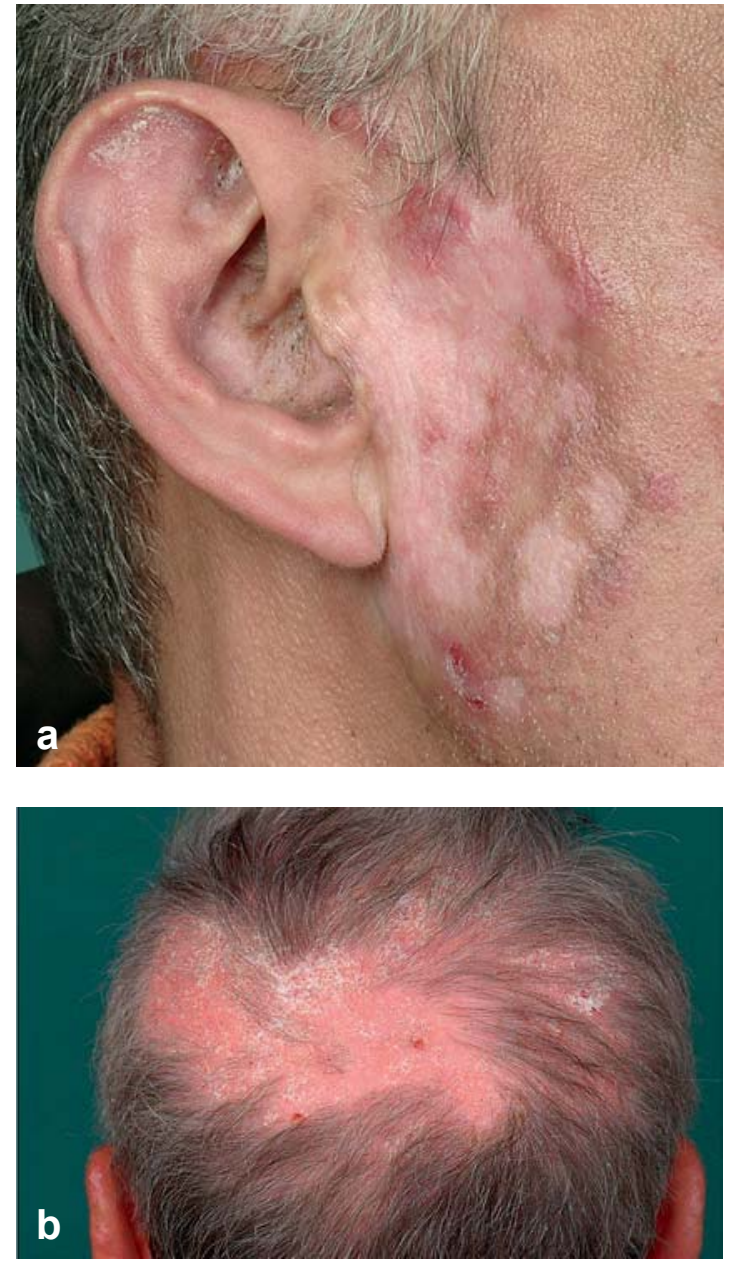

the major causes of mortality in SLE (4). The most common form of pulmonary involvement is dry or wet pleurisy (40 to 60\%); lupus pneumonitis and pulmonary fibrosis are rare (2). The central nervous system is affected in about 15 to $50 \%$ of patients with SLE, but due to the low specificity (e.g., headache) and high variability of the symptoms, their identification as part of SLE often proves difficult $(2,12)$. Besides neuropsychiatric manifestations such as cognitive deficits, psychosis, and depression, organic brain syndromes, epileptic seizures, and transverse myelitis may occur, as well as vascular events (e.g., vasculitis, arterial/venous thrombosis in the case of antiphospholipid antibodies) and peripheral neuropathy $(12, \mathrm{e} 13)$.

\section{Laboratory diagnostics}

If SLE is suspected based on clinical findings, laboratory testing can support the diagnosis. At first, a screening laboratory test is recommended $(2,8,10,13)$ (Box
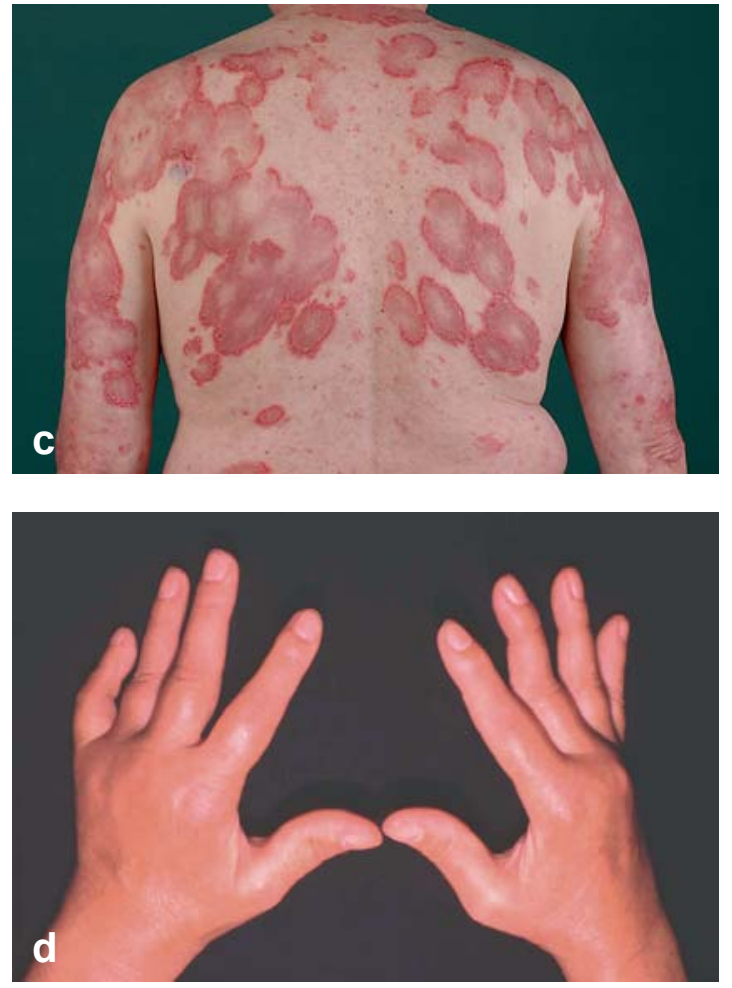

Figure 1:

a) Discoid lupus erythematosus (DLE) on the right cheek and ear: scarring with hyperpigmented border and residual activity (preauricular erythema with keratosis on the earlobe and comedo-like lesions in the meatus);

b) Discoid lupus erythematosus (DLE) on the scalp: confluence of several lesions with erythema, silvery-white adherent hyperkeratoses and scarring alopecia, as well as DLE on the ear;

c) Subacute cutaneous lupus erythematosus (SCLE) on the back and the extensor surface of the arms: polycyclic confluence of annular erythematous lesions with collarette scaling at the inner border and central clearing;

d) Joint deformation without radiologic erosions (Jaccoud arthropathy)

2). A high erythrocyte sedimentation rate is characteristic for active SLE; C-reactive protein is usually normal or only slightly elevated. A standard or differential blood count may reveal cytopenias such as thrombocytopenia and/or leukopenia and lymphopenia, as well as further hematological changes such as autoimmune hemolytic anemia (e13). Renal parameters should include serum creatinine, urinary status and sediment. Antinuclear antibodies (AI A) should be analyzed by indirect immunofluorescence tests (HEp-2 cells) (Figure 2b).

In patients with positive AI A and a homogeneous fluorescence pattern it is useful to determine anti-dsDI A antibodies. The findings of ELISA (high sensitivity, low specificity) should be confirmed by radioimmunoassay (RIA, also known as Farr assay; high specificity, suitable for monitoring) (14, e14). An alternative to the RIA, which is not available in all laboratories due to its requirement of radioactive material, 

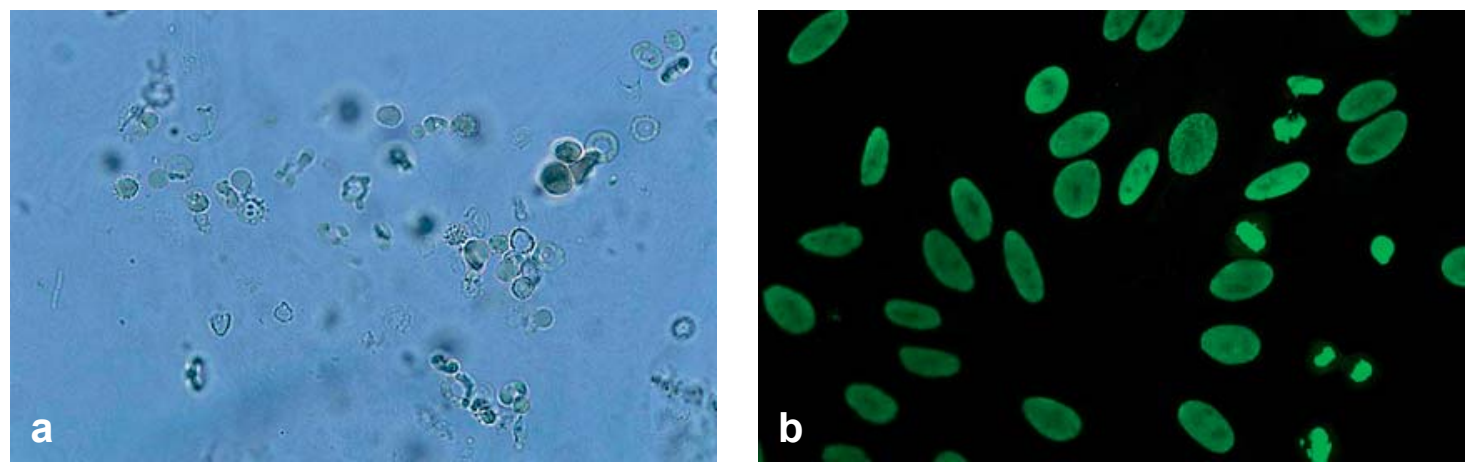

Figure 2:

a) "Active" urinary sediment in lupus nephritis: if more than $5 \%$ of all erythrocytes in the urine show the appearance of so-called acanthocytes ("Micky Mouse ears"), glomerulonephritis is probable. Simultaneous albuminuria supports the suspicion;

b) Antinuclear antibodies (ANA; HEp-2 cell test): homogeneous pattern with positive mitoses

is the Crithidia luciliae immunofluorescence test (high specificity, low sensitivity). In addition to anti-dsDI A antibodies (prevalence 70 to $98 \%$ ), anti-Sm antibodies (prevalence 14 to $40 \%$ ) are specific marker antibodies of SLE $(14,15$, e10). C3 and C4 should be determined as indicators of complement consumption or deficiency.

The course of SLE is characterized by exacerbations and remissions; however, the AI A titer does not correlate with disease activity. In contrast, anti-dsDI A antibodies often rise several months before a disease flare, in parallel with a decrease of complement factors $(16,17)$. As a consequence, disease activity should be closely monitored-particularly with regard to renal involvement.

\section{Additional diagnostics}

Further diagnostic investigations depend on the symptoms of SLE and should be carried out in cooperation with medical specialists from the appropriate disciplines. In the case of cutaneous manifestations, a dermatologist should be consulted for a biopsy of the skin and/or oral mucous membrane lesions (histology/ immunofluorescence) for purposes of differential diagnosis (e15). For further investigations see Box 3.

\section{Assessment of activity and damage}

For the determination of disease activity in SLE, various scoring systems have been developed (SLEDAI, SLAM, BILAG, ECLAM) that mainly include clinical findings and laboratory parameters (18). These scores enable standardized evaluation of disease activity, which is the basis for every therapy decision. Therefore, the European League Against Rheumatism (EULAR) recommends the use of a standardized score for assessment of disease activity at every visit. It is important to distinguish activity and damage, as the damage cannot be treated with immunosuppressive agents. The damage should be assessed annually using the SLICC/ACR Damage Index for SLE (Systemic Lupus International Collaborating Clinics/American
College of Rheumatology) (19). The CLASI (Cutaneous Lupus Erythematosus Disease Area and Severity Index) and the RCLASI (Revised Cutaneous Lupus Erythematosus Disease Area and Severity Index) were developed and validated to assess disease activity and damage of mucocutaneous manifestations (20, e16).

\section{Treatment}

The treatment of SLE is based on the results of only few randomized controlled trials. Furthermore, the inclusion criteria of these studies were not uniform, with heterogeneous disease severity and low patient numbers. I evertheless, internationally consented recommendations for the treatment of patients with SLE have been developed (Tables 1 and 2) (10, 12, 21).

\section{Antimalarial agents}

In every patient with SLE treatment with antimalarials is recommended unless there are contraindications (21-23). The action of antimalarials is based on, among other factors, the inhibition of activation of intracellular toll-like receptors (e17). Hydroxychloroquine and chloroquine are licensed for the treatment of SLE. Apart from their good efficacy against arthritis and LE-specific skin lesions (8), antimalarials maintain SLE in remission, are associated with fewer disease flares, and reduce damage in the course of the disease $(23$, e18). In lupus nephritis, cohort studies have demonstrated positive effects for hydroxychloroquine or chloroquine administered before (24), and for hydroxychloroquine as adjunct to standard treatment after the diagnosis of renal involvement $(10,25$, e19). Furthermore, the positive impact of antimalarials on lipid and glucose metabolism have been described, as well as a reduction of thromboembolisms with a favorable influence on cardiovascular risk in SLE, and antineoplastic effects have been discussed $(22,23)$. Based on the experience of experts, the continuation of hydroxychloroquine treatment during pregnancy is recommended, 


\section{Investigations in suspected systemic lupus erythematosus (SLE) and monitoring after diagnosis}

- Screening laboratory tests*1

- Erythrocyte sedimentation rate

- Blood count, differential blood count

- Creatinine

- Urinary status and sediment

- Antinuclear antibodies (ANA) (HEp-2 cell test with fluorescence pattern)

- Further laboratory tests after positive screening*1

(particularly in case of positive ANA)*1

- Further differentiation of ANA (particularly anti-Sm, -Ro/SSA, -La/SSB, -U1RNP antibodies, etc.)

- Anti-dsDNA antibodies (ELISA; confirmation by radioimmunoassay or immunofluorescence test with Crithidia luciliae)

- Complement C3, C4

- Antiphospholipid antibodies, lupus anticoagulant

- Glomerular filtration rate; 24-hour urine (if urine protein positive), alternatively: protein/creatinine ratio in single urine sample; investigation for dysmorphic erythrocytes in sediment

- Liver enzymes; lactate dehydrogenase; creatine kinase in presence of muscular symptoms

- Further laboratory tests depending on clinical symptoms

- Screening for comorbidities

- Assessment of vaccination status (vaccination recommendations [in German] at http://dgrh.de/impfempfehlung.html)

- Follow-up (SLE: every 3 to 6 months depending on disease course; lupus nephritis: initially every 2 to 4 weeks for the first 2 to 4 months) ${ }^{\star 2}$

- Medical history (including new symptoms, comedication, infections), physical examination

- Evaluate disease activity with standardized score

- Evaluate damage according to standardized score (1 x/year)

- Repeat screening for comorbidities (at least $1 \times /$ year)

- Ocular examination in patients taking hydroxychloroquine or chloroquine: baseline, then every 6 months (currently being revised by the German Society of Rheumatology in light of recommendations from the USA) (e30, e31)

- Laboratory tests

- Erythrocyte sedimentation rate

- C-reactive protein (in suspected infection or pleurisy)

- Blood count, differential blood count

- Creatinine

- Liver enzymes

- Urinary status (protein/creatinine ratio, 24-hour urine and microscopic examination of urinary sediment as needed)

- Complement C3, C4

- Anti-dsDNA antibodies

- Instrument-based diagnostics as needed

\section{BOX 3}

\section{Organ-specific diagnostics as required}

- Skin/oral mucous membrane

- Biopsy: histology, immunofluorescence if indicated

- Joints

- Conventional X-ray

- Arthrosonography

- Magnetic resonance imaging (MRI)

- Muscle

- Creatine kinase

- Electromyography

- MRI

- Muscle biopsy

- Kidney

- Sonography

- Renal biopsy

- Lung/heart

- Chest X-ray

- Thoracic high-resolution computed tomography (HR-CT)

- Lung function test including diffusion capacity

- Bronchoalveolar lavage

- (Transesophageal) echocardiography

- Cardiac catheterization

- Cardiac MRI

- Myocardial scintigraphy

- Coronary angiography

- Eye

- Funduscopy/special investigations in patients on antimalarials

- Central and peripheral nervous system

- Electroencephalography

- Primarily cranial MRI, special MRI techniques if indicated

- Computed tomography

- Cerebrospinal fluid analysis

- Transcranial Doppler/angiography

- Neuropsychiatric examination

- Measurement of nerve conduction velocity

*1 Modified after $(2,8),{ }^{* 2}$ modified after $(2,8,10,13,21)$ 
TABLE 1

Treatment recommendations for systemic lupus erythematosus (SLE) with no, mild, and/or moderate organ manifestations (e.g., skin, joints, serositis)

\begin{tabular}{|c|c|c|c|c|}
\hline Indication & Medication & $\begin{array}{l}\text { Level of } \\
\text { evidence }\end{array}$ & Strength of statement & Dosage \\
\hline First line and basic treatment & $\begin{array}{l}\text { Hydroxychloroquine } \\
\text { or } \\
\text { Chloroquine } \\
\text { If indicated, initial non- } \\
\text { steroidal anti-inflamma- } \\
\text { tory drugs } \\
\text { and/or } \\
\text { glucocorticoids }\end{array}$ & $2(21)$ & $A(21)$ & $\begin{array}{l}\leq 6.0-6.5 \mathrm{mg} / \mathrm{kg} \text { ideal body weight/day } \\
\leq 3.5-4.0 \mathrm{mg} / \mathrm{kg} \text { ideal body weight/day } \\
\text { Calculation of ideal body weight: } \\
\text { - Men: [Height minus 100] minus } 10 \% \\
\text { - Women: [Height minus 100] minus } 15 \%\end{array}$ \\
\hline $\begin{array}{l}\text { If no response or no reduc- } \\
\text { tion of glucocorticoids } \\
\leq 7.5 \mathrm{mg} \text { possible in the long } \\
\text { term }\end{array}$ & $\begin{array}{l}\text { Azathioprine } \\
\text { or } \\
\text { methotrexate } \\
\text { or } \\
\text { mycophenolate mofetil }\end{array}$ & $\begin{array}{l}4(21) \\
2(21) \\
6(21)\end{array}$ & $\begin{array}{l}B(21) \\
A(21) \\
D(21)\end{array}$ & $\begin{array}{l}\text { 2-3 mg/kg body weight/day } \\
15-20 \mathrm{mg} / \text { week (preferably s.c.) } \\
2 \mathrm{~g} / \text { day }\end{array}$ \\
\hline $\begin{array}{l}\text { Adjunct treatment in } \\
\text { autoantibody-positive SLE } \\
\text { with high disease activity } \\
\text { despite standard treatment } \\
\text { (e27) }\end{array}$ & Belimumab & - & & $\begin{array}{l}10 \mathrm{mg} / \mathrm{kg} \text { body weight i.v. infusion ( } 1 \mathrm{~h} \text { ) initially, then after } \\
14 \text { days and subsequently every } 4 \text { weeks }\end{array}$ \\
\hline \multicolumn{5}{|c|}{$\begin{array}{l}\text { Remarks: } \\
\text { - According to expert opinion, not only low-dose prednisone but also hydroxychloroquine and azathioprine (particularly in lupus nephritis [10]) can be } \\
\text { administered in pregnancy (e20). } \\
\text { - In case of comedication with mycophenolate mofetil and proton pump inhibitors, the bioavailability of mycophenolate mofetil is reduced; a switch to } \\
\text { mycophenolic acid is advisable (e32). } \\
\text { - Proton pump inhibitors may lower the efficacy of hydroxychloroquine/chloroquine (e33). } \\
\text { - Treatment and monitoring instructions of the DGRh (in German) for the above-mentioned medications for use by patients and physicians can be found at } \\
\text { www.dgrh.de/therapieueberwachen.html }\end{array}$} \\
\hline
\end{tabular}

DGRh, German Society of Rheumatology

${ }^{*}$ In patients with lupus nephritis, mycophenolate mofetil and i.v. cyclophosphamide have recently shown comparable efficacy with regard to total non-renal disease activity (39, 40)

as SLE patients on hydroxychloroquine show lower disease activity and fewer exacerbations and need lower doses of glucocorticoids at the time of birth (26, e20). Hydroxychloroquine can also be continued during breastfeeding (26, e21).

The dose of hydroxychloroquine and chloroquine depends on the maximal daily dose, calculated on the basis of ideal body weight (Table 1). If the actual body weight is lower than the ideal body weight, actual body weight should be used for calculation of the maximum daily dose (27). The dreaded side effect of irreversible retinopathy (bull's eye maculopathy) was, particularly in earlier years, associated with excessive daily dosages $(28$, e22). In advanced renal failure (GFR $<30 \mathrm{~mL} / \mathrm{min}$ ), the daily dose of antimalarial medication should be modified accordingly; in patients on dialysis it should be reduced to $15 \%$ of the standard dose $(10,22)$.

Hydroxychloroquine is preferentially used in SLE, but in case of intolerance or lack of efficacy chloroquine can be administered instead (8). The optimal efficacy of antimalarials is often not observed before 3 to 6 months of therapy. LE-specific skin lesions, however, may respond after 4 to 6 weeks $(8$, e22).
If no improvement of the cutaneous manifestations is seen after 3 to 6 months of treatment, hydroxychloroquine or chloroquine can be combined with the antimalarial agent mepacrine (synonym quinacrine; off label, no ocular toxicity) in a dosage of no more than $100 \mathrm{mg} /$ day $(8,28)$.

Smoking has been suggested to decrease the effect of antimalarials; therefore, SLE patients should be advised to cease smoking completely. A few case reports and our own experience even show that therapy-refractory skin lesions were thereby resolved (e23, e24).

\section{Topical treatment}

Glucocorticoids are the topical treatment of choice for skin lesions in SLE (evidence level III) (8). Class IV glucocorticoids (e.g., clobetasol) can be applied to the scalp, palms, and soles, whereas in other areas only class II (e.g., methylprednisolone aceponate) and class III (e.g., mometasone furoate) glucocorticoids are recommended. Due to the adverse effects (e.g., atrophy, teleangiectasia, perioral dermatitis) glucocorticoids should be administered only intermittently and not long term, particularly not for butterfly rash. 
Treatment recommendations on the example of proliferative lupus nephritis class III-IV in systemic lupus erythematosus with active organ involvement (ISN/RPS, International Society of Nephrology/Renal Pathology Society 2003 Classification of Lupus Nephritis) (11)

\begin{tabular}{|c|c|c|c|c|}
\hline Indication & Medication & $\begin{array}{l}\text { Level of } \\
\text { evidence }\end{array}$ & Strength of statement & Dosage \\
\hline $\begin{array}{l}\text { Continuation of treatment } \\
\text { with antimalarials }\end{array}$ & Hydroxychloroquine & $3(10)$ & $C(10)$ & $\leq 6.0-6.5 \mathrm{mg} / \mathrm{kg}$ ideal body weight/day \\
\hline Induction therapy & $\begin{array}{l}\text { Combination of } \\
\text { glucocorticoids } \\
\text { with: } \\
\text { mycophenolate mofetil } \\
\text { or } \\
\text { cyclophosphamide } \\
\text { (low-dose) i.v. } \\
\text { or } \\
\text { azathioprine }\end{array}$ & $\begin{array}{l}1(10) \\
1(10) \\
2(10)\end{array}$ & $\begin{array}{l}A(10) \\
B(10) \\
B(10)\end{array}$ & 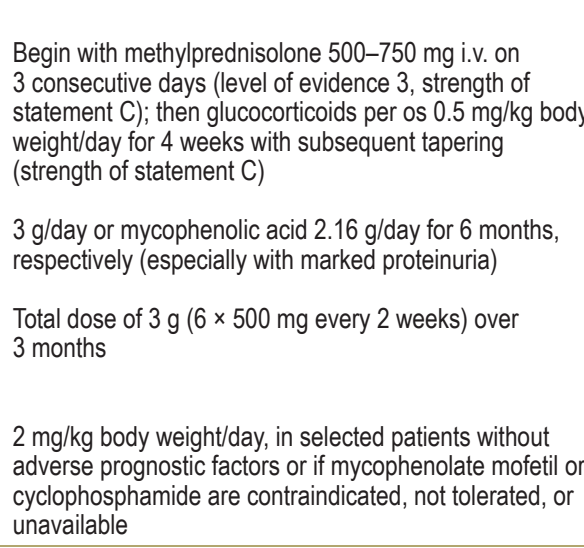 \\
\hline $\begin{array}{l}\text { Maintenance treatment after } \\
\text { response to induction } \\
\text { therapy }\end{array}$ & $\begin{array}{l}\text { Combination of low- } \\
\text { dose glucocorticoids } \\
\text { with: } \\
\text { mycophenolate mofetil } \\
\text { or } \\
\text { azathioprine* }\end{array}$ & $\begin{array}{l}1(10) \\
1(10)\end{array}$ & $\begin{array}{l}A(10) \\
A(10)\end{array}$ & $\begin{array}{l}5.0-7.5 \mathrm{mg} / \text { day prednisone } \\
2 \mathrm{~g} / \text { day or mycophenolic acid } 1.44 \mathrm{~g} / \text { day } \\
2 \mathrm{mg} / \mathrm{kg} \text { body weight/day } \\
\text { mycophenolate mofetil or azathioprine for } 3 \text { years, } \\
\text { respectively (level of evidence } 3 \text {, strength of statement } \\
\text { C); then begin with slow tapering of glucocorticoids }\end{array}$ \\
\hline $\begin{array}{l}\text { Refractory to therapy, or } \\
\text { contraindication }\end{array}$ & $\begin{array}{l}\text { Calcineurin inhibitors } \\
\text { (cyclosporine A, tacroli- } \\
\text { mus) } \\
\text { Rituximab (anti-CD20) }\end{array}$ & $\begin{array}{l}- \\
-\end{array}$ & & \\
\hline
\end{tabular}

\section{Remarks:}

- According to expert opinion, not only low-dose prednisone but also hydroxychloroquine and azathioprine (particularly in lupus nephritis [10]) can be administered in pregnancy (e20).

- In case of comedication with mycophenolate mofetil and proton pump inhibitors, the bioavailability of mycophenolate mofetil is reduced; a switch to mycophenolic acid is advisable (e32).

- Proton pump inhibitors may lower the efficacy of hydroxychloroquine/chloroquine (e33).

- Treatment and monitoring instructions of the DGRh (in German) for the above-mentioned medications for use by patients and physicians can be found at www.dgrh.de/therapieueberwachen.html

DGRh, German Society of Rheumatology

*The MAINTAIN study shows comparable results for mycophenolate mofetil and azathioprine (only presented as an abstract at the American College of Rheumatology [ACR] conference in 2014: Tamirou F. et al: The 10-year follow up of nephritis trial comparing azathioprine and mycophenolate mofetil for longterm immunosuppression of lupus nephritis. Arthritis Rheum 2014; 66: 426-7).

An alternative is the off-label use of topical calcineurin inhibitors (tacrolimus ointment [level of evidence I], pimecrolimus cream [level of evidence II]). These agents can be applied as long-term treatment without the above-mentioned risks associated with the extended use of glucocorticoids (e.g. in butterfly rash, lupus erythematosus tumidus, initial DLE) (29, e25).

\section{Immunosuppressive treatment}

In patients without organ-threatening manifestations (e.g., LE-specific skin lesions, arthritis, pleurisy), long-term treatment with antimalarials should be sufficient. Due to the delayed onset of action of antimalarials, most patients temporarily need additional, short-term effective medication, usually non-steroidal anti-inflammatory drugs or glucocorticoids. If glucocorticoids cannot be reduced to a dosage of 5 to $7.5 \mathrm{mg}$ /day prednisolone equivalent or discontinued within a reasonable period of time, the EULAR recommends - even for patients without organ involvement-administration of immunosuppressives such as azathioprine, methotrexate, or mycophenolate mofetil to spare glucocorticoids $(21,30)$. Methotrexate may have a favorable effect on joint and skin lesions and on general disease activity $(8,21,31)$.

Two phase III studies with a total of 1684 patients indicate that treatment with belimumab is a further 
effective option in SLE (e26). In 2012, belimumab was approved as an adjunct therapy for adult patients with autoantibody-positive SLE who despite standard therapy show high disease activity, intolerance of other treatments for SLE, or an unacceptably high need for glucocorticoids (Table 1) (e27). The most frequently occurring adverse effects include nausea, diarrhea, and bacterial and viral infections (e.g., bronchitis, cystitis, and pharyngitis), as well as hypersensitivity/infusion reactions. Data on the efficacy of belimumab in routine clinical practice are limited (32, e26).

The next level of treatment is indicated in the presence of active organ involvement, particularly when the kidneys and/or central nervous system are affected. The EULAR has recently published guidelines for the management of neuropsychiatric manifestations of SLE (12). The main goal is to identify cases of antiphospholipid syndrome, which requires anticoagulation and not immunosuppression. Otherwise, immunosuppressive treatment of SLE with organ involvement is mainly based on the experience with lupus nephritis $(10,33)$.

Mycophenolate mofetil (or mycophenolic acid in an equivalent dose) and low-dose intravenous cyclophosphamide in combination with glucocorticoids are available as induction therapy for proliferative lupus nephritis (class III-IV), depending on the best risk-benefit ratio (Table 2) (10). For patients who respond to initial treatment, the recommended maintenance therapy is lower immunosuppression, with either mycophenolate mofetil/mycophenolic acid or azathioprine for at least 3 years in combination with lowdose prednisone. Thereafter, a gradual reduction of the medication can be attempted, beginning with tapering of glucocorticoids. Until recently, mycophenolate mofetil or mycophenolic acid were described as superior to azathioprine for the maintenance therapy of lupus nephritis, but the 10-year data from the MAII TAII study and current meta-analyses do not confirm the previous findings (Table 2) (34).

Although SLE is usually more severe in childhood and adolescence, there are no randomized controlled trials of treatment in this age group. The treatment is based on data from adults and begins with hydroxychloroquine and glucocorticoids (35). In the presence of serious organ involvement (kidneys, central nervous system), early pulse therapy with cyclophosphamide and/or glucocorticoids is indicated. Mycophenolate mofetil is increasingly becoming an alternative to cyclophosphamide. Azathioprine and cyclosporine can be used as steroid-sparing medications. Patients are currently being recruited for a pediatric study of treatment with belimumab (e28).

\section{Adjunct treatment}

Almost as important as immunosuppression is the comedication, which is determined by the comorbidities (infections, arteriosclerosis, hypertension, dyslipidemia, diabetes, osteoporosis, avascular necrosis, and malignan- cies, among others) and the damage that has already occurred $(13,21,30)$. Weight control and adequate exercise are further important aspects. Depending on the medication prescribed and the clinical situation, the use of low-dose aspirin, calcium, vitamin D, bisphosphonates, statins, and blood pressure drugs (especially ACE inhibitors in proteinuria) should be considered. Immunosuppressed patients should be vaccinated (particularly against influenza and pneumococci); vaccinations with live attenuated vaccines are contraindicated (Box 2) (36).

Prophylactic measures comprise ultraviolet (UV) light protection, abstinence from smoking, and avoidance of medications known to trigger SLE (e.g., hydralazine and TI F-alpha antagonists; the reader is referred to the literature) $(8,37)$. Consistent light protection includes wearing sun protective clothing, keeping the head covered, and using sun blockers with chemical and/or physical UV-A/UV-B filters (SPF 50+). These should be applied 20 to $30 \mathrm{~min}$ before UV exposure in sufficient amounts $\left(2 \mathrm{mg} / \mathrm{cm}^{2}\right)(38$, e29). SLE patients should be informed that UV-A radiation penetrates window glass (including that in vehicles).

\section{Conclusion}

Advances in diagnostics, optimized treatment (also of comorbidities), and regular monitoring of disease activity and damage have clearly improved the prognosis of SLE. The goal of treatment is remission or at least minimization of disease activity and prevention of flares. I owadays, antimalarials are the basic treatment for every patient with SLE, whereas glucocorticoids should only be used when acutely indicated. If reduction

\section{KEY MESSAGES}

- Systemic lupus erythematosus (SLE) is a heterogeneous disease that may affect many different organs; early diagnosis prevents adverse consequences and clearly improves the prognosis.

- The diagnosis of SLE is symptom-based and often requires an interdisciplinary approach. Depending on the organ(s) involved, patients with SLE should be referred to qualified medical specialists with long-term experience in the treatment of this disease or to a dedicated SLE center.

- The goal of treatment is remission or control of disease activity and prevention of (further) organ damage with the minimum possible dose of glucocorticoids.

- Treatment with the drugs available can clearly improve the short- and long-term prognosis of SLE. Antimalarials should be used-unless contraindicated_in all patients with SLE.

- A modern treatment strategy should comprise not only preventive measures but also the treatment of comorbidities (e.g., infections and cardiovascular events). 
or tapering of glucocorticoids proves impossible, extended immunosuppression with azathioprine, methotrexate, or mycophenolate mofetil is recommended. Should the patient fail to respond, belimumab can be administered.

Although mycophenolate mofetil is not officially approved for use in SLE, there is now international consensus that its good efficacy with low toxicity make this agent an effective alternative to short-term administration of low-dose intravenous cyclophosphamide in the induction therapy for proliferative lupus nephritis.

\section{Conflict of interest statement \\ Prof. Kuhn has received consultancy fees from Biogen, GlaxoSmithKline (GSK) Grünenthal, and Lilly. She has received reimbursement of costs for conference attendance, travel, and accommodation as well as payments for the prepara- tion of scientific meetings from Basilea, Biogen, GSK, La Roche Posay, Lilly, and Spirig Pharma GmbH.}

She has received support for the conduct of commissioned clinical studies related to the topic of this article from Actelion, Basilea, Biogen Idec, Centocor La Roche Posay, Lilly, and Spirig Pharma GmbH.

She has received remuneration for her own research related to the topic of this article from Actelion, Basilea, Biogen Idec, Centocor, La Roche Posay, Lilly, and Spirig Pharma GmbH.

Prof. Anders has received consultancy fees from GSK and honoraria for the preparation of scientific meetings from Roche and GSK

Prof. Herzer has received consultancy fees from GSK.

Prof. Schneider has received consultancy fees from GSK, UCB, Lilly, and AstraZeneca and honoraria for the preparation of scientific meetings from GSK. He has received remuneration for his own research from GSK and UCB.

PD Dr. Tenbrock and Dr. Bonsmann declare that no conflict of interest exists.

Manuscript received on 10 September 2014, revised version accepted on 13 April 2015.

Translated from the original German by David Roseveare.

\section{REFERENCES}

1. Cervera R, Khamashta MA, Font J, et al.: Systemic lupus erythematosus: clinical and immunologic patterns of disease expression in a cohort of 1,000 patients. The European Working Party on Systemic Lupus Erythematosus. Medicine (Baltimore) 1993; 72: 113-24.

2. Fischer-Betz R, Herzer P, Schneider M: Systemischer Lupus erythematodes. [Systemic lupus erythematosus]. Dtsch Med Wochenschr 2005; 130: 2451-8.

3. Brinks R, Fischer-Betz R, Sander 0, Richter JG, Chehab G, Schneider M: Age-specific prevalence of diagnosed systemic lupus erythematosus in Germany 2002 and projection to 2030. Lupus 2014; 23: 1407-11.

4. Chehab G, Fischer-Betz R, Schneider M: Entwicklung von Mortalität und Morbidität beim systemischen Lupus erythematodes. [Changes in mortality and morbidity in systemic lupus erythematosus]. Z Rheumatol 2011; 70: 480-5.

5. Cervera R, Khamashta MA, Font J, et al.: Morbidity and mortality in systemic lupus erythematosus during a 10-year period: a comparison of early and late manifestations in a cohort of 1,000 patients. Medicine (Baltimore) 2003; 82: 299-308.

6. Hochberg MC: Updating the American College of Rheumatology revised criteria for the classification of systemic lupus erythematosus. Arthritis Rheum 1997; 40: 1725.

7. Deutsche Gesellschaft für Rheumatologie e. V. - Diagnose \& Klassifikation. www.dgrh.de/kriterienassessments.html (last accessed on 19 March 2015).

8. Kuhn A, Aberer E, Barde C, et al.: Leitlinien Kutaner Lupus Erythematosus (Entwicklungsstufe 1). In: Korting H, Callies R,
Reusch M, Schlaeger M, Sterry W (eds.): Dermatologische Qualitätssicherung: Leitlinien und Empfehlungen. Berlin: ABW Wissenschaftsverlag GmbH 2009; 214-57.

9. Petri M, Orbai AM, Alarcon GS, et al.: Derivation and validation of the Systemic Lupus International Collaborating Clinics classification criteria for systemic lupus erythematosus. Arthritis Rheum 2012; 64: 2677-86

10. Bertsias GK, Tektonidou M, Amoura Z, et al.: Joint European League Against Rheumatism and European Renal AssociationEuropean Dialysis and Transplant Association (EULAR/ERA-EDTA) recommendations for the management of adult and paediatric lupus nephritis. Ann Rheum Dis 2012; 71: 1771-82.

11. Weening JJ, D'Agati VD, Schwartz MM, et al.: The classification of glomerulonephritis in systemic lupus erythematosus revisited J Am Soc Nephrol 2004; 15: 241-50.

12. Bertsias GK, loannidis JP, Aringer M, et al.: EULAR recommendations for the management of systemic lupus erythematosus with neuropsychiatric manifestations: report of a task force of the EULAR standing committee for clinical affairs. Ann Rheum Dis 2010; 69: 2074-82

13. Mosca M, Tani C, Aringer M, et al.: European League Against Rheumatism recommendations for monitoring patients with systemic lupus erythematosus in clinical practice and in observational studies. Ann Rheum Dis 2010; 69: 1269-74.

14. Hartung K, Seelig HP: Labordiagnostik der systemischen Autoimmunerkrankungen. Teil 1. Kollagenosen. [Laboratory diagnostics of systemic autoimmune diseases. Part 1. Collagenoses]. Z Rheumatol 2006; 65: 709-22.

15. Cozzani E, Drosera M, Gasparini G, Parodi A: Serology of lupus erythematosus: correlation between immunopathological features and clinical aspects. Autoimmune Dis 2014; 2014: 321359.

16. Pan N, Amigues I, Lyman $\mathrm{S}$, et al.: A surge in anti-dsDNA titer predicts a severe lupus flare within six months. Lupus 2014; 23: $293-8$.

17. ter Borg EJ, Horst G, Hummel EJ, Limburg PC, Kallenberg CG Measurement of increases in anti-double-stranded DNA antibody levels as a predictor of disease exacerbation in systemic lupus erythematosus. A long-term, prospective study. Arthritis Rheum 1990; 33: 634-43.

18. Ward MM, Marx AS, Barry NN: Comparison of the validity and sensitivity to change of 5 activity indices in systemic lupus erythematosus. J Rheumatol 2000; 27: 664-70.

19. Gladman D, Ginzler E, Goldsmith C, et al.: The development and initial validation of the Systemic Lupus International Collaborating Clinics/American College of Rheumatology damage index for systemic lupus erythematosus. Arthritis Rheum 1996; 39: 363-9.

20. Kuhn A, Meuth AM, Bein D, et al.: Revised Cutaneous Lupus Erythematosus Disease Area and Severity Index (RCLASI): a modified outcome instrument for cutaneous lupus erythematosus. Br J Dermatol 2010; 163: 83-92.

21. Bertsias G, loannidis JP, Boletis J, et al.: EULAR recommendations for the management of systemic lupus erythematosus. Report of a Task Force of the EULAR Standing Committee for International Clinical Studies Including Therapeutics. Ann Rheum Dis 2008; 67: 195-205.

22. Fischer-Betz R, Schneider M: Antimalariamittel. Therapieoption für jeden Lupus-Patienten?! [Antimalarials. A treatment option for every lupus patient?!]. Z Rheumatol 2009; 68: 6-90.

23. Ruiz-Irastorza G, Khamashta MA: Hydroxychloroquine: the cornerstone of lupus therapy. Lupus 2008; 17: 271-3.

24. Siso A, Ramos-Casals M, Bove A, et al.: Previous antimalarial therapy in patients diagnosed with lupus nephritis: influence on outcomes and survival. Lupus 2008; 17: 281-8.

25. Pons-Estel GJ, Alarcon GS, McGwin G, et al.: Protective effect of hydroxychloroquine on renal damage in patients with lupus 
nephritis: LXV, data from a multiethnic US cohort. Arthritis Rheum 2009; 61: 830-9.

26. Fischer-Betz R: Rheumatische Erkrankungen in der Schwangerschaft. [Rheumatic diseases during pregnancy]. Internist 2012; 53: 1047-53.

27. Kuhn A, Ruland V, Bonsmann G: Hautmanifestationen des Lupus erythematodes: Klinik und Therapie. [Skin manifestations in lupus erythematosus: clinical aspects and therapy]. Z Rheumatol 2011; 70: 213-26.

28. Ochsendorf FR: Einsatz von Antimalariamitteln in der Dermatologie. [Use of antimalarials in dermatology]. J Dtsch Dermatol Ges 2010; 8: 829-44.

29. Kuhn A, Gensch K, Haust M, et al.: Efficacy of tacrolimus $0.1 \%$ ointment in cutaneous lupus erythematosus: a multicenter randomized, double-blind, vehicle-controlled trial. J Am Acad Dermatol 2011; 65: 54-64, e1-2.

30. Schneider M: EULAR-Empfehlungen zur Behandlung des systemischen Lupus erythematodes. [EULAR recommendations for the management of systemic lupus erythematosus]. Z Rheumatol 2009; 68: 578, 80-3.

31. Sakthiswary R, Suresh E: Methotrexate in systemic lupus erythematosus: a systematic review of its efficacy. Lupus 2014; 23: 225-35.

32. Fischer-Betz R, Schneider M, Kommission Pharmakotherapie der DGRh: Empfehlungen zum Einsatz von Belimumab beim systemischen Lupus erythematodes. [Recommendation for use of belimumab for systemic lupus erythematosus]. Z Rheumatol 2013; 72: 462-7.

33. Henderson L, Masson P, Craig JC, et al.: Treatment for lupus nephritis. Cochrane Database Syst Rev 2012; 12: CD002922.

34. Maneiro JR, Lopez-Canoa N, Salgado E, Gomez-Reino JJ: Maintenance therapy of lupus nephritis with mycophenolate or azathioprine: systematic review and meta-analysis. Rheumatology (Oxford) 2014; 53: 834-8.

35. Tenbrock K, Horneff G: Leitlinien Systemischer Lupus erythematodes (Entwicklungsstufe 1). Leitlinie der Gesellschaft für
Kinder- und Jugendrheumatologie und der Deutschen Gesellschaft für Kinder- und Jugendmedizin 2013; 1-8.

36. van Assen S, Agmon-Levin N, Elkayam 0, et al.: EULAR recommendations for vaccination in adult patients with autoimmune inflammatory rheumatic diseases. Ann Rheum Dis 2011; 70: 414-22.

37. Katz U, Zandman-Goddard G: Drug-induced lupus: an update Autoimmun Rev 2010; 10: 46-50

38. Faurschou A, Wulf HC: The relation between sun protection factor and amount of sunscreen applied in vivo. $\mathrm{Br} \mathrm{J}$ Dermatol 2007; 156: 716-9.

39. Aringer M, Fischer-Betz R, Hiepe F: Stellungnahme zum Einsatz von Mycophenolat-Mofetil beim systemischen Lupus erythematodes. [Statement on the use of mycophenolate mofetil for systemic lupus erythematosus]. Z Rheumatol 2013; 72: 575-80.

40. Ginzler EM, Wofsy D, Isenberg D, Gordon C, Lisk L, Dooley MA: Nonrenal disease activity following mycophenolate mofetil or intravenous cyclophosphamide as induction treatment for lupus nephritis: findings in a multicenter, prospective, randomized, openlabel, parallel-group clinical trial. Arthritis Rheum 2010; 62 : 211-21.

\section{Corresponding author}

Prof. Dr. med. Annegret Kuhn, MBA

Interdisziplinäres Zentrum Klinische Studien (IZKS)

Universitätsmedizin der Johannes Gutenberg-Universität Mainz

55131 Mainz, Germany

office@izks-unimedizin-mainz.de

For eReferences please refer to:

www.aerzteblatt-international.de/ref2515

eTable:

www.aerzteblatt-international.de/15m0423 


\title{
The Diagnosis and Treatment of Systemic Lupus Erythematosus
}

\author{
Annegret Kuhn, Gisela Bonsmann, Hans-Joachim Anders, Peter Herzer, \\ Klaus Tenbrock, Matthias Schneider
}

\section{eREFERENCES}

e1. Bertsias G, Cervera R, Boumpas D: Systemic lupus erythematosus: pathogenesis and clinical features. In: Bijlsma J (ed.): EULAR textbook on rheumatic diseases. London: BMJ Group 2012; 476-505.

e2. Fischer-Betz R, Schneider M: Früher Lupus erythematodes. [Early lupus erythematosus]. Z Rheumatol 2013; 72: 948-53.

e3. Pineles D, Valente A, Warren B, Peterson MG, Lehman TJ, Moorthy LN: Worldwide incidence and prevalence of pediatric onset systemic lupus erythematosus. Lupus 2011; 20: 1187-92.

e4. Cervera R, Khamashta MA, Font J, et al.: Morbidity and mortality in systemic lupus erythematosus during a 5-year period. A multicenter prospective study of 1,000 patients. European Working Party on Systemic Lupus Erythematosus. Medicine (Baltimore) 1999; 78: 167-75.

e5. Danza A, Ruiz-Irastorza G: Infection risk in systemic lupus erythematosus patients: susceptibility factors and preventive strategies. Lupus 2013; 22: 1286-94.

e6. Swaak AJ, Nossent JC, Smeenk RJ: Prognostic factors in systemic lupus erythematosus. Rheumatol Int 1991; 11: 127-32.

e7. Bongu A, Chang E, Ramsey-Goldman R: Can morbidity and mortality of SLE be improved? Best Pract Res Clin Rheumatol 2002; 16: 313-32.

e8. Urowitz MB, Gladman DD: Evolving spectrum of mortality and morbidity in SLE. Lupus 1999; 8: 253-5.

e9. Tan EM, Cohen AS, Fries JF, et al.: The 1982 revised criteria for the classification of systemic lupus erythematosus. Arthritis Rheum 1982; 25: 1271-7.

e10. Jimenez S, Cervera R, Ingelmo M, Font J: The epidemiology of cutaneous lupus erythematosus. In: Kuhn A, Lehmann P, Ruzicka T (eds.): Cutaneous lupus erythematosus. Berlin: Springer-Verlag 2004; 45-52.

e11. Gilliam JN, Sontheimer RD: Distinctive cutaneous subsets in the spectrum of lupus erythematosus. J Am Acad Dermatol 1981; 4: 471-5.

e12. Kuhn A, Ruzicka T: Classification of cutaneous lupus erythematosus. In: Kuhn A, Lehmann P, Ruzicka T (eds.): Cutaneous lupus erythematosus. Heidelberg, Berlin, New York: Springer Verlag 2004; 53-9.

e13. Kleinert S, Feuchtenberger M, Tony HP: Systemischer Lupus erythematodes. Eine problemorientierte Annäherung. [Systemic lupus erythematosus. A problem based approach]. Internist (Berl) 2010; 51: 1013-26.

e14. Jaekell HP, Trabandt A, Grobe N, Werle E: Anti-dsDNA antibody subtypes and anti-C1q antibodies: toward a more reliable diagnosis and monitoring of systemic lupus erythematosus and lupus nephritis. Lupus 2006; 15: 335-45.

e15. Sepehr A, Wenson S, Tahan SR: Histopathologic manifestations of systemic diseases: the example of cutaneous lupus erythematosus. J Cutan Pathol 2010; 37: 112-24.

e16. Albrecht J, Taylor L, Berlin JA, et al.: The CLASI (Cutaneous Lupus Erythematosus Disease Area and Severity Index): an outcome instrument for cutaneous lupus erythematosus. J Invest Dermatol 2005; 125: 889-94.

e17. Lafyatis R, York M, Marshak-Rothstein A: Antimalarial agents: closing the gate on Toll-like receptors? Arthritis Rheum 2006; 54: 3068-70. e18. Fessler BJ, Alarcon GS, McGwin G, et al.: Systemic lupus erythematosus in three ethnic groups: XVI. Association of hydroxychloroquine use with reduced risk of damage accrual. Arthritis Rheum 2005; 52: 1473-80.

e19. Kasitanon N, Fine DM, Haas M, Magder LS, Petri M: Hydroxychloroquine use predicts complete renal remission within 12 months among patients treated with mycophenolate mofetil therapy for membranous lupus nephritis. Lupus 2006; 15: 366-70.

e20. Iozza I, Cianci S, Di Natale A, et al.: Update on systemic lupus erythematosus pregnancy. J Prenat Med 2010; 4: 67-73.

e21. Clowse ME, Magder L, Witter F, Petri M: Hydroxychloroquine in lupus pregnancy. Arthritis Rheum 2006; 54: 3640-7.

e22. Mavrikakis M, Papazoglou S, Sfikakis PP, Vaiopoulos G, Rougas K: Retinal toxicity in long term hydroxychloroquine treatment. Ann Rheum Dis 1996; 55: 187-9.

e23. Kuhn A, Sigges J, Biazar C, et al.: Influence of smoking on disease severity and antimalarial therapy in cutaneous lupus erythematosus: analysis of 1002 patients from the EUSCLE database. Br J Dermatol 2014; 171: 571-9.

e24. Kreuter A, Gaifullina R, Tigges C, Kirschke J, Altmeyer P, Gambichler T: Lupus erythematosus tumidus: response to antimalarial treatment in 36 patients with emphasis on smoking. Arch Dermatol 2009; 145: 244-8.

e25. Sardy M, Ruzicka T, Kuhn A: Topical calcineurin inhibitors in cutaneous lupus erythematosus. Arch Dermatol Res 2009; 301: 93-8.

e26. Manzi S, Sanchez-Guerrero J, Merrill JT, et al.: Effects of belimumab, a B lymphocyte stimulator-specific inhibitor, on disease activity across multiple organ domains in patients with systemic lupus erythematosus: combined results from two phase III trials. Ann Rheum Dis 2012; 71: 1833-8.

e27. Gemeinsamer Bundesausschuss: Dossier zur Nutzenbewertung gemäß §35a SGBV - Belimumab (Benlysta) Modul 1. www.g-ba.de/downloads/92- 975-94/ 2012-01-27_Modul1_Belimumab.pdf? (last accessed on 19 March 2015).

e28. Barsalou J, Levy DM, Silverman ED: An update on childhood-onset systemic lupus erythematosus. Curr Opin Rheumatol 2013; 25: 616-22.

e29. Kuhn A, Ruland V, Bonsmann G: Cutaneous lupus erythematosus: update of therapeutic options part I. J Am Acad Dermatol 2011; 65: e179-93.

e30. Marmor MF, Kellner U, Lai TY, Lyons JS, Mieler WF: Revised recommendations on screening for chloroquine and hydroxychloroquine retinopathy. Ophthalmology 2011; 118: 415-22.

e31. Marmor MF, Carr RE, Easterbrook M, Farjo AA, Mieler WF: Recommendations on screening for chloroquine and hydroxychloroquine retinopathy: a report by the American Academy of Ophthalmology. Ophthalmology 2002; 109: 1377-82.

e32. Xu L, Cai M, Shi BY, Li ZL, Li X, Jin HL: A prospective analysis of the effects of enteric-coated mycophenolate sodium and mycophenolate mofetil co-medicated with a proton pump inhibitor in kidney transplant recipients at a single institute in China. Transplant Proc 2014; 46: 1362-5.

e33. Namazi MR: The potential negative impact of proton pump inhibitors on the immunopharmacologic effects of chloroquine and hydroxychloroquine. Lupus 2009; 18: 104-5. 


\section{eTABLE}

Lupus erythematosus (LE)-specific cutaneous manifestations (Duesseldorf classification of cutaneous lupus erythematosus)*

\begin{tabular}{|c|c|}
\hline Subtype & Characteristics \\
\hline Acute cutaneous lupus erythematosus (ACLE) & $\begin{array}{l}\text { - Localized: "butterfly rash" } \\
\text { - Generalized: maculopapular exanthema } \\
\text { - Oral mucous membrane: erosions, ulcers } \\
\text { - Diffuse thinning of hairline ("lupus hair") }\end{array}$ \\
\hline Subacute cutaneous lupus erythematosus (SCLE) & $\begin{array}{l}\text { - Annular and/or papulosquamous/psoriasiform with polycyclic confluence } \\
\text { - Healing without scarring, vitiligo-like hypopigmentation } \\
\text { - High photosensitivity } \\
\text { - } 70-90 \% \text { anti-Ro/SSA and in 30-50\% anti-La/SSB antibodies } \\
\text { - } \geq 4 \text { ACR criteria in } 50 \% \text {, development of a mild form of systemic lupus erythematosus in } \\
\text { 10-15\% (rarely involvement of kidneys and central nervous system) }\end{array}$ \\
\hline \multicolumn{2}{|l|}{ Chronic cutaneous lupus erythematosus (CCLE) } \\
\hline Discoid lupus erythematosus (DLE) & $\begin{array}{l}\text { - Localized (ca. } 80 \% \text { ) or disseminated (ca. 20\%) } \\
\text { - Discoid erythematous plaques with firmly adherent follicular hyperkeratoses } \\
\text { - Healing with scarring (on the scalp, scarring alopecia) }\end{array}$ \\
\hline Chilblain lupus erythematosus (CHLE) & $\begin{array}{l}\text { - Tender, livid red swelling, sometimes with erosion/ulceration } \\
\text { - Localization: symmetrical, cold-exposed areas of extremities }\end{array}$ \\
\hline Lupus erythematosus profundus/panniculitis (LEP) & $\begin{array}{l}\text { - Subcutaneous, nodular/plaque-like, dense infiltrates } \\
\text { - Ulceration and calcification possible, healing with scarring and deep lipatrophy }\end{array}$ \\
\hline \multicolumn{2}{|l|}{ Intermittent cutaneous lupus erythematosus (ICLE) } \\
\hline Lupus erythematosus tumidus (LET) & $\begin{array}{l}\text { - Erythematous, urticaria-like, edematous plaques without epidermal involvement } \\
\text { - High photosensitivity } \\
\text { - Variable course, healing without scarring }\end{array}$ \\
\hline
\end{tabular}

${ }^{*}$ Modified after (8) 